\title{
Comparison of methanol/hydrochloric, ferric chloride acid versus tribochemical silica coating for adhesion of resin cement to zirconium dioxide
}

\author{
Rodrigo Furtado de Carvalho, Mutlu Özcan, Frederico Louzada, Evelyn \\ Monteiro, Marco Antonio Bottino, Renata Marques de Melo \& Luiz Felipe \\ Valandro
}

To cite this article: Rodrigo Furtado de Carvalho, Mutlu Özcan, Frederico Louzada, Evelyn Monteiro, Marco Antonio Bottino, Renata Marques de Melo \& Luiz Felipe Valandro (2016) Comparison of methanol/hydrochloric, ferric chloride acid versus tribochemical silica coating for adhesion of resin cement to zirconium dioxide, Journal of Adhesion Science and Technology, 30:24, 2690-2698, DOI: 10.1080/01694243.2016.1197090

To link to this article: https://doi.org/10.1080/01694243.2016.1197090

曲 Published online: 16 Jun 2016.

Submit your article to this journal $\widetilde{ }$

凹 Article views: 101

View Crossmark data $\subset$ 


\title{
Comparison of methanol/hydrochloric, ferric chloride acid versus tribochemical silica coating for adhesion of resin cement to zirconium dioxide
}

\author{
Rodrigo Furtado de Carvalho o, Mutlu Özcan ${ }^{\mathrm{b}}$, Frederico Louzadac, Evelyn Monteiroc, \\ Marco Antonio Bottinoc, Renata Marques de Meloc and Luiz Felipe Valandro ${ }^{d}$
}

aDepartment of Dentistry, Federal University of Juiz de Fora (UFJF), Governador Valadares, Brazil; ${ }^{b}$ Dental Materials Unit, Center for Dental and Oral Medicine, Clinic for Fixed and Removable Prosthodontics and Dental Materials Science, Zurich, Switzerland; 'Dental School, Science and Technology Institute, São Paulo State University (UNESP), Sao Jose dos Campos, Brazil; ${ }^{d}$ Department of Restorative Dentistry, Federal University of Santa Maria (UFSM), Division of Prosthodontics, Santa Maria, Brazil

\begin{abstract}
This study compared air-abrasion and etching regimens on adhesion of resin luting agent to zirconium dioxide. Ceramic specimens (LAVA, 3 M ESPE) ( $N=16$ ) were embedded in acrylic resin and exposed surfaces were polished. The specimens were randomly assigned into four groups ( $n=12,3$ specimens for each disc): SC: Air-borne particle abrasion (30 $\mu \mathrm{m}$ aluminum oxide particles coated with silica, CoJet, 3 M ESPE); MH: Heated chemical solution (Methanol-800 mL; 37\% Hydrochloric Acid-200 mL; Ferric Chloride-2 g) at $100{ }^{\circ} \mathrm{C}$ for $30 \mathrm{~min}$, MHP: Primer (Metal/Zirconia Primer, Ivoclar Vivadent) + MH, P: Primer only (Metal/Zirconia Primer). Cylindrical molds (internal diameter: $0.7 \mathrm{~mm}$; height: $1.5 \mathrm{~mm}$ ) were placed on each conditioned specimen, filled with resin cement (Multilink Automix) and photo-polymerized for $60 \mathrm{~s}$. After $24 \mathrm{~h}$, the molds were removed and the specimens were stored in distilled water at $37{ }^{\circ} \mathrm{C}$ for six months). Microshear test was performed in a Universal Testing Machine $(1 \mathrm{~mm} / \mathrm{min})$. Failures types were classified as adhesive, mixed, or cohesive. In another set of specimens ( $n=2$ per group) contact angle measurements were recorded. Data were analyzed statistically using KruskalWallis and Dunn's tests $(a=0.05)$. The surface conditioning method significantly affected the mean bond strength (MPa) $(p<0.0001)$ : $\mathrm{SC}(18.3 \pm 0.3)^{\mathrm{a}}<P(5.00 \pm 0.07)^{\mathrm{b}}<\mathrm{MHP}(4.7 \pm 0.08)^{\mathrm{c}}<\mathrm{MH}(0.84 \pm 0.01)^{\mathrm{c}}$. While Group SC showed mainly adhesive (58\%) and mixed (41.7\%) failure types, groups $\mathrm{MH}, \mathrm{MHP}$, and $\mathrm{P}$ presented exclusively adhesive failures. SC, MHP, and P $\left(29-32^{\circ}\right)$ showed lower contact angle than $\mathrm{MH}\left(78.9^{\circ}\right)$. Volume loss was the highest with MHP $(9.92 \mu \mathrm{l})$ followed by $\mathrm{SC}(9.67 \mu \mathrm{l})$.
\end{abstract}

\section{ARTICLE HISTORY}

Received 14 March 2016

Revised 29 May 2016

Accepted 31 May 2016

\section{KEYWORDS}

Adhesion; air-abrasion; cementation; ceramics; etching; microshear bond test; surface conditioning; zirconia

\section{Introduction}

Yttrium-stabilized zirconium dioxide (zirconia) ceramic is one of the most commonly used industrially manufactured machinable block for CAD/CAM technology, with flexural 
strength of 900-1200 MPa being higher than other types of ceramics such as feldspar and lithium disilicate ceramics.[1]

The performance of reconstructions made of zirconia is not only related to its strength, but also to the cementation procedures especially for minimal invasive applications where chemical composition of the ceramic, surface conditioning methods and the cement types play significant roles on the durability of adhesion.[2] Since zirconia does not contain a glass phase but high crystalline content neither etching with hydrofluoric acid nor silanization that is commonly performed for glass ceramics, could provide appropriate bonding between zirconia and adhesive cement.[3] The use of phosphate monomer-based primers and cements have been demonstrated to form some adhesion similar to that produced by silanes through hydroxyl groups. However, the bond strength values reported in the literature using such chemical agents still seem to be lower than those values achieved after air-borne particle abrasion of zirconia with $\mathrm{Al}_{2} \mathrm{O}_{3}$ particles coated with silica $(30-50 \mu \mathrm{m})$. [4] This method, called tribochemical silica coating, provides micro-retentions and leaves silica remnants on the surface, allowing mechanical and chemical bonding between silane coupling agent and the resin cement.[5] In this context, the use of zirconia coupling agents or primers was also indicated on conditioning pure zirconia.[6] Such coupling agents establish covalent bonds between the silane and the hydroxyl groups of zirconia and improve the wettability and adhesion of resin cements. Unfortunately, zirconia coupling agents display a significant decrease in bond strength after hydrothermal aging. [6] Thus, alternative methods have been proposed [7-9] one of which is etching zirconia using heated chemical solutions.[10-12] Such chemical solutions were postulated to produce surface irregularities and deliver increased bond strength between resin cement and zirconia when compared to air-abrasion with $125 \mu \mathrm{m} \mathrm{Al}_{3} \mathrm{O}_{2}$ particles or no conditioning.[7,11] However, their longterm stability after aging conditions is not known. When long-term stability of adhesion of resin cements are achieved using etching solutions to condition zirconia frameworks, they may serve as alternative surface conditioning modalities and substitute air-abrasion as the latter may yield to phase transformation from tetragonal to monoclinic which may be detrimental for the longevity of the zirconia reconstructions.

The objectives of this study therefore were to evaluate the effect of acid etching zirconia with heated acidic solution vs. tribochemical silica coating on the adhesion of resin cement after aging conditions and analyze the failure types. The null hypothesis tested was that bond strength would not significantly differ between surface conditioning methods tested.

\section{Materials and Methods}

\section{Preparation of specimens}

Zirconia specimens $(N=16)$ (LAVA, 3 M ESPE, St. Paul., Minn, USA) were prepared according to the manufacturer's recommendations (diameter: $15 \mathrm{~mm}$; height: $2 \mathrm{~mm}$ ). The specimens were wet ground finished using silicon carbide papers in sequence (\#400,600, $800,1200,1500,2000)$ for $30 \mathrm{~s}$ each. After sintering $\left(1.500^{\circ} \mathrm{C}, 11 \mathrm{~h}\right.$, Lava Therm Sintering furnace, 3 M ESPE), the specimens were cleaned ultrasonically (Vitasonic, VITA Zahnfabrik, Bad Säckingen, Germany) in distilled water for $10 \mathrm{~min}$. The specimens were then embedded in auto-polymerized acrylic resin (VIPI Flash, VIPI, Pirassununga, Brazil) with the bonding surfaces exposed, using a device that maintained the specimens parallel to the $x$-axis. 
The specimens were then randomly allocated (http://www.randomizer.org/) into the four groups.

\section{Surface conditioning methods}

Group SC: The specimens were air-abraded with $30 \mu \mathrm{m}$ aluminum oxide particles coated with silica (CoJet Sand, 3 M ESPE) using a custom-made holder [13] at a constant pressure of 2.8 bar from a distance of approximately $15 \mathrm{~mm}$ from the surface, in a circular motion. After drying the surface with oil-free air, silane coupling agent (Monobond S, Ivoclar Vivadent, Schaan, Liechtenstein) was applied and allowed for its reaction with the substrate surface for $5 \mathrm{~min}$.

Group MH: Zirconia surfaces were etched with heated solution (Methanol-800 mL, 37\% hydrochloric acid-200 mL, and ferric chloride- $2 \mathrm{~g}$ ) at $100{ }^{\circ} \mathrm{C}$ for $30 \mathrm{~min}$ in an autoclave (Phoenix AV model 100, Biosystems, Santa Cândida, Brazil).[11]

Group MHP: After the zirconia surfaces were etched as described in Group MH, silane coupling agent (Metal/Zirconia Primer, Ivoclar Vivadent) was applied with a clean brush one coat and allowed to react with the surface for $5 \mathrm{~min}$.

Group P: In this group, zirconia surfaces received only silane coupling agent (Metal/ Zirconia Primer) as described in Group MHP.

\section{Adhesive cementation}

A resin-based luting cement (Multilink Automix, Ivoclar Vivadent) was bonded to the conditioned zirconia surfaces for microshear bond test.[14] Three translucent cylinder molds (Tygon tubing, TYG-030, Maime Lakes, FL, USA) (internal diameter: $0.7 \mathrm{~mm}$; height: $1.5 \mathrm{~mm}$ ) were fixed with wax on the conditioned substrate surfaces ( $n=12$ per group, three specimens for each disc). The resin was manipulated according to the manufacturer's recommendations and applied using a syringe $(0.5 \mathrm{~mL})$ to fill the cylinder molds and photo-polymerized (Optilux 501, Demeton, Kerr, Orange, USA; light intensity: $850 \mathrm{mW/}$ $\mathrm{cm}^{2}$ ) for $60 \mathrm{~s}$.

After storage in distilled water at $37^{\circ} \mathrm{C}$ for $24 \mathrm{~h}$, the cylinder molds were removed using sharp blades (Gillette, Sao Paulo, SP, Brazil), exposing the resin cylinders. All cylinders were examined with stereomicroscope (SteREO Discovery V12; Carl Zeiss, Gottingen, Germany) at $\times 30$ magnification to check for the defects at the bonding interface.

The specimens were then stored in distilled water at $37^{\circ} \mathrm{C}$ for 6 months.

\section{Microshear bond strength test}

The specimens were placed in device attached to the jig of the Universal Testing Machine (EMIC, DL 1000, Sao Jose dos Pinhais, PR, Brasil) for microshear test. A wire loop (diameter: $0.2 \mathrm{~mm}$ ) surrounded the cement cylinder, making contact through half of its circumference and was carefully maintained at the zirconia-cement interface. A shear force was applied to the bonded interface at a speed of $1 \mathrm{~mm} / \mathrm{min}$ until failure. The wire loop and the center of the load cell (10 Kgf) were aligned to ensure that the shear forces were correctly oriented. Bond strength $(\mathrm{MPa})$ was obtained dividing the load at failure $(N)$ by the interfacial bonding area $\left(0.38 \mathrm{~mm}^{2}\right)$. 


\section{Failure analysis}

Failure analysis of all specimens was performed using a stereomicroscope (SteREO Discovery.V12, Carl Zeiss) at $\times 20$ to $\times 200$ magnification. The failures were classified as: adhesive (failure at the zirconia-cement interface with no cement remnants left adhered on the surface), cohesive (failure in the ceramic or cement), or mixed (combination of adhesive and cohesive failures).

\section{Contact angle measurement}

On separate specimens $(n=2)$ contact angle was measured using goniometer (Thetalite II, Biolin Scientific, Inc., Baltimore, USA) connected to a computer using software (Attension, Biolin Scientific, Inc., Baltimore, USA) at $26^{\circ} \mathrm{C}$. One deionized water drop was placed on the zirconia surface using a syringe and the contact angle was measured after $10 \mathrm{~s}$, allowing water spread on the surface, using 30 frames per second.

\section{Topographical analysis}

Topography of zirconia surfaces after surface conditioning methods were analyzed using scanning electron microscope (SEM) (JSM-5600LV, Jeol, Tokyo, Japan), at ×2000 magnification on separate specimens ( $n=2$ per group).

\section{Statistical analysis}

All statistical procedures were performed using the Statistical Package for Medical Science (SPSS 21.00 for Windows software, SPSS Inc., Chicago, IL, USA). The data were expressed as median, minimum, and maximum values. Descriptive statistics were computed, and test of normality was performed using Kolmogorov-Smirmov and Shapiro-Wilk's tests. Mean bond strength $(\mathrm{MPa})$ data were analyzed using Kruskal-Wallis and Dunn's test. $P$ values less than 0.05 were considered to be statistically significant in all tests.

\section{Results}

The surface conditioning method significantly affected the mean bond strength $(\mathrm{MPa})$ $(p<0.0001): \operatorname{SC}(18.3 \pm 0.3)^{\mathrm{a}}<\operatorname{MHP}(5.00 \pm 0.07)^{\mathrm{b}}<\mathrm{P}(4.7 \pm 0.08)^{\mathrm{c}}<\mathrm{MH}(0.84 \pm 0.01)^{\mathrm{c}}$ (Table 1) indicating more favorable results with physicochemical conditioning methods compared to chemical methods.

SC, MHP, and $P\left(29-32^{\circ}\right)$ showed lower contact angle than $\mathrm{MH}\left(78.9^{\circ}\right)$. Volume loss was the highest with MHP $(9.92 \mu \mathrm{l})$ followed by SC $(9.67 \mu \mathrm{l})$ showing similar trends with the adhesion results (Table 1).

While Group SC showed mainly adhesive (58\%) and mixed (41.7\%) failure types, groups $\mathrm{MH}, \mathrm{MHP}$, and P presented exclusively adhesive failures. No cohesive failures were observed in any of the groups (Table 2, Figures 1(a)-(d)).

SEM photos of MHP and P groups revealed no penetration of the primer to the conditioned zirconia surface (Figures 2(a)-(b)). The MH group presented similar surface topography with conditioned zirconia $(P)$, indicating no major morphological changes. 
Table 1. The means and standard deviations of microshear bond strength (MPa), contact angle, volume, baseline values for the experimental groups.

\begin{tabular}{lcccc}
\hline Experimental groups & Bond strength $(\mathrm{MPa})$ & Contact angle $\left(^{\circ}\right)$ & Volume $(\mu \mathrm{l})$ & Baseline $(\mathrm{mm})$ \\
\hline SC & $18.3(0.30)^{\mathrm{A}}$ & $28.52(0.54)$ & $9.67(0.09)$ & $4.86(0.01)$ \\
MH & $0.8(0.10)^{\mathrm{C}}$ & $78.88(0.23)$ & $8.45(0.10)$ & $5.42(0.02)$ \\
MHP & $5.1(0.07)^{\mathrm{B}}$ & $29.98(0.49)$ & $9.92(0.18)$ & $4.79(0.02)$ \\
P & $4.7(0.08)^{\mathrm{B}}$ & $31.49(0.17)$ & $8.82(0.08)$ & $4.98(0.01)$ \\
\hline
\end{tabular}

Note. The same capital superscripted letters in each column indicate no significant differences $(a=0.05)$. SC: Air-borne particle abrasion ( $30 \mu \mathrm{m}$ aluminum oxide particles coated with silica, CoJet, $3 \mathrm{M} \mathrm{ESPE);} \mathrm{MH:} \mathrm{Heated} \mathrm{chemical} \mathrm{solution}$ (Methanol-800 mL; 37\% Hydrochloric Acid-200 mL; Ferric Chloride-2 g) at $100{ }^{\circ} \mathrm{C}$ for $30 \mathrm{~min}, \mathrm{MHP}: \mathrm{MH}+$ Primer (Metal/ Zirconia Primer, Ivoclar Vivadent), P: Primer only (Metal/Zirconia Primer).

Table 2. The incidence of failure types (\%) for the experimental groups. A: Adhesive failure along the interfacial region between the resin cement and the zirconia surface; $C$ : Cohesive failure in the resin cement, M: Mixed failure (cohesive failure of the resin cement combined with adhesive failure). See Table 1 for group abbreviations.

\begin{tabular}{lc}
\hline Experimental groups & Failure types (\%) \\
\hline SC & $A(58.3) C(0) M(41.7)$ \\
MH & $A(100) C(0) M(0)$ \\
MHP & $A(100) C(0) M(0)$ \\
P & $A(100) C(0) M(0)$ \\
\hline
\end{tabular}

\section{Discussion}

This study aimed to evaluate the effect of acid etching zirconia with heated acidic solution vs. tribochemical silica coating on the adhesion of resin cement after aging conditions. Based on the results of this study, since surface condition method significantly affected the bond strength results, the null hypothesis was rejected.

Previous studies have shown that most critical failures of highly crystalline ceramics begin at the cementation-substrate surfaces.[15,16] Therefore, the integrity of the luting cement to zirconia surface is an important factor for the longevity of the adhesively luted restorations. The present study evaluated whether surface conditioning protocols based on etching with heated solution could be an alternative to tribochemical coating to improve adhesion of resin cement after aging. The results in the absence of chemical bond were not favorable for etching after aging, contradicting with the previous studies. $[7,11,12]$ The morphological evaluation under SEM indicated rough surface after this type of conditioning but SC groups yielded to more prominent surface alterations for increased mechanical retention, confirming previous findings of studies on adhesion to zirconia.[3,5,13] The heated acidic solution seemed to have no evident effect in terms of surface change on the zirconia presenting similarities with the Group P specimens that were polished and silanized only. These findings were similar to the findings presented in a microscopy study where the presence of slight scratches on the surface treated with a heated solution was demonstrated.[12]

The low bond strength results were also supported by the contact angle measurements in Group MH. The higher contact angle indicates less surface wettability and bond potential.[2] The contact angle was significantly higher in MH compared to SC, MHP, and $P$ groups where the latter three received a coat of silane. The silane and primer increase the surface energy of the ceramic and improve the wettability of the cement, thus optimizing the substrate-cement interaction.[6] One study noted penetration of flowable resin cement 


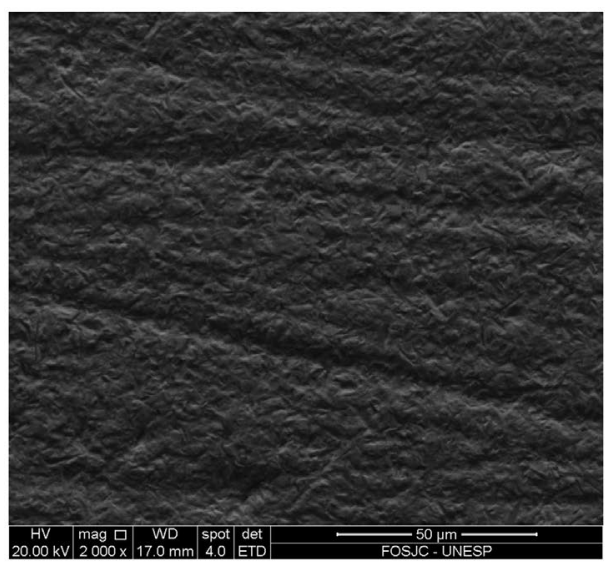

(a)

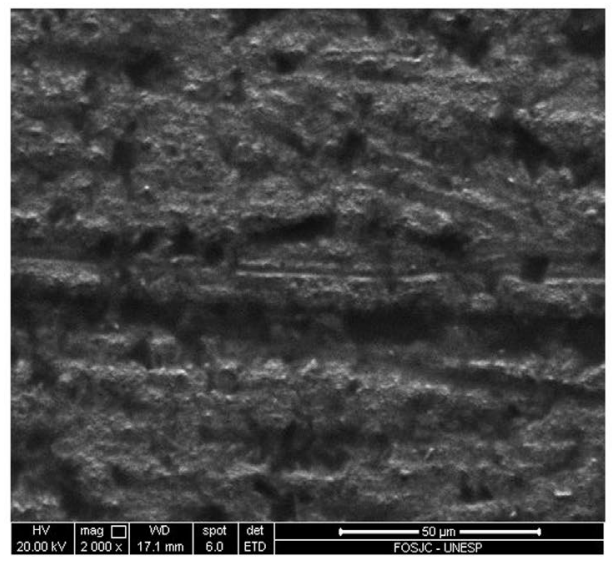

(c)

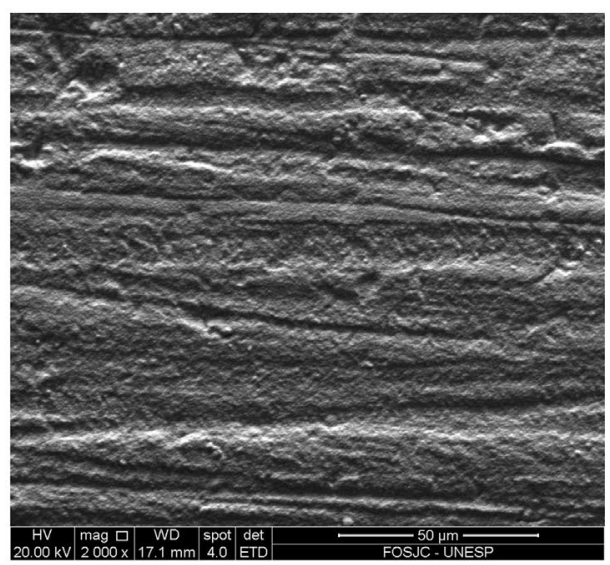

(b)

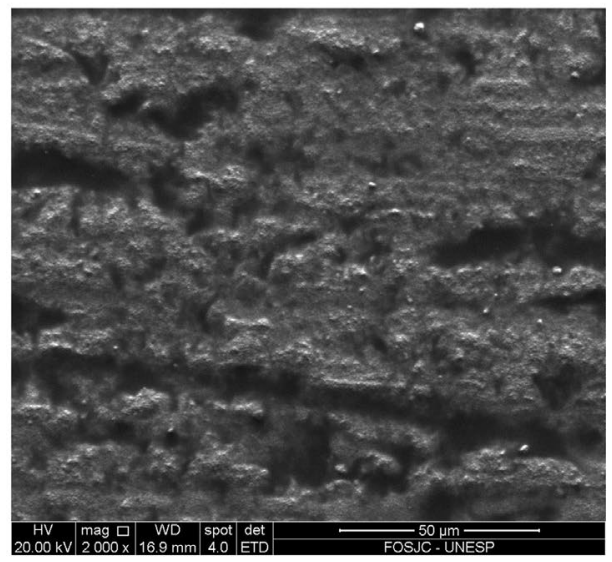

(d)

Figure 1. Representative SEM photomicrographs $(\times 2000)$ of zirconia surface after various surface conditioning methods tested: (a) Silica coating (SC), (b) Conditioning with the heated solution $(\mathrm{MH})$, (c) Heated solution + Primer (MHP), (d) Primer (P).

into the microretentions caused by the heated solution.[11] Considering the contact angle measurements of the present study, the surface roughening could not be considered sufficient to create long-lasting interaction, although the cement used in the current study was not the same as the cement used in the previous study.[11]

A controversial aspect in relation to the air-abrasion procedures is the possible damaging effect of particles on the mechanical properties of zirconia. It has been previously reported that this type of surface conditioning induces phase transformation from tetragonal to monoclinic zirconia, yielding to increased resistance to fracture.[1] On the other hand, other studies reported structural defects after air-abrasion that makes ceramics more susceptible to fracture during function. $[5,17,18]$ In terms of adhesion, silica coating in this study delivered the highest results, in line with previous studies.[19-23] Thus, surface conditioning with heated solution could not substitute air-abrasion for improved adhesion. 


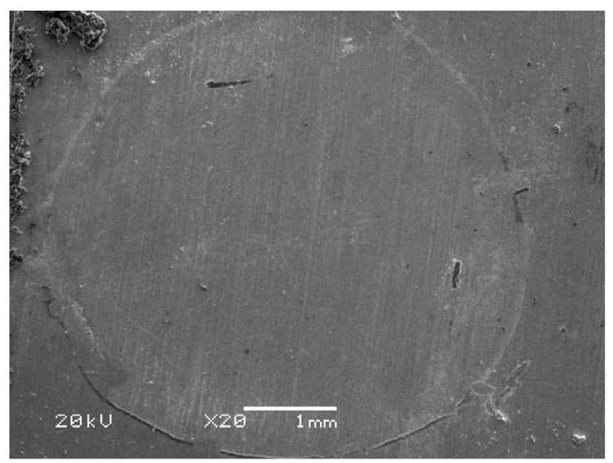

(a)

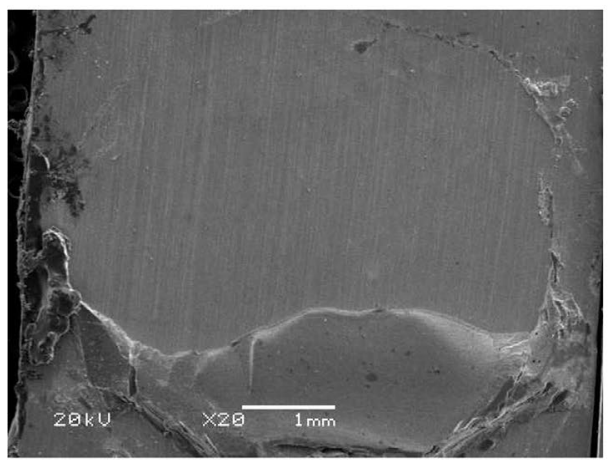

(b)

Figure 2. Representative micrographs of the failure modes from the tested specimens, (a) adhesive failure type at the ceramic-cement interface at the zirconia-cement interface with no cement remnants left adhered on the surface, (b) mixed failure (combination of adhesive and cohesive failure in the cement. The indicator $(*)$ represents the zirconia surface free of resin cement, while the pointer $(x)$ indicates the resin cement surface.

The heated solution might generate a selective etching effect on zirconia, creating and expanding micro-retentions in grain boundaries by removing less organized grains and providing peripheral atoms with high energy.[8,24] Although zirconia-based ceramics show high resistance to acidic corrosion, immersion in a heated acid solution could cause rupture of the surface layer of zirconia and generate localized corrosion.[11] However, the findings of the current study did not support this assumption, as the adhesion obtained with the use of acidic solution was not long lasting. In fact, water can penetrate into nanometric spaces, resulting in decreased thermal stability of the polymer and causing a plasticizing effect. [25] Due to the small size of the specimens, instead of thermocycling, long-term storage in distilled water was practiced to age the bonded interfaces.

Shear bond testing leads to complex stress concentration at the adhesive interface, not only exerting shear forces, but also tensile forces, in the region near the site of load application, leading to cohesive failures.[26-29] However, the majority of the failures in this study were adhesive, except for SC group, which showed high incidence of mixed failures (41.7\%).

According to results of this present study, heated methanol-hydrochloric acid-ferric chloride solution with and without the application of primer could not substitute tribochemical silica coating and silanization. Apparently, optimal mechanical interlocking and chemical adhesion through primer in physicochemical conditioning still provides the most durable adhesion of resin cement to zirconia. Future studies should also evaluate phase transformation after etching with heated chemical solutions that is the limitation of this study.

\section{Conclusions}

From this study, the following could be concluded:

(1) Surface conditioning method significantly affected the mean bond strength of resin cement to zirconia where silica coating and silanization delivered significantly higher bond strength compared to the application of heated chemical 
solution (methanol, 37\% hydrochloric acid and ferric chloride) without and with primer.

(2) The incidences of mixed failure types were more frequent in the silica coated group, whereas all other groups with and without etching regimens presented exclusively adhesive failures. No cohesive failures were observed in any of the groups.

(3) Volume loss was the highest after application of chemical solution followed by silica coating, but they both demonstrated lower contact angle.

\section{Clinical relevance}

Heated chemical solution of methanol, $37 \%$ hydrochloric acid and ferric chloride at $100{ }^{\circ} \mathrm{C}$ for $30 \mathrm{~min}$, with and without primer application cannot substitute air-abrasion with silica coating and silanization for better adhesion of resin cement to zirconia.

\section{Conflict of interest}

The authors did not have any commercial interest in any of the materials used in this study.

\section{References}

[1] Guazzato M, Albakry M, Ringer SP, et al. Strength, fracture toughness and microstructure of a selection of all-ceramic materials. Part II. Zirconia-based dental ceramics. Dent. Mater. 2004;20:449-456.

[2] Della Bona A, Anusavice KJ. Microstructure, composition, and etching topography of dental ceramics. Int. J. Prosthodont. 2002;15:159-167.

[3] Amaral R, Özcan M, Bottino MA, et al. Microtensile bond strength of a resin cement to glass infiltrated zirconia-reinforced ceramic: the effect of surface conditioning. Dent. Mater. 2006;22:283-290.

[4] Yun JY, Ha SR, Lee JB, et al. Effect of sandblasting and various metal primers on the shear bond strength of resin cement to Y-TZP ceramic. Dent. Mater. 2010;26:650-658.

[5] Bhargava S, Doi H, Kondo R, et al Effect of sandblasting on the mechanical properties of Y-TZP zirconia. Biomed. Mater. Eng. 2012;22:383-398.

[6] Matinlinna JP, Lassila LV. Enhanced resin-composite bonding to zirconia framework after pretreatment with selected silane monomers. Dent. Mater. 2011;27:273-280.

[7] Casucci A, Osorio E, Osorio R, et al. Influence of different surface treatments on surface zirconia frameworks. J. Dent. 2009;37:891-897.

[8] Oyagüe RC, Monticelli F, Toledano M, et al. Effect of water aging on microtensile bond strength of dual-cured resin cements to pre-treated sintered zirconium-oxide ceramics. Dent. Mater. 2009;25:392-399.

[9] Attia A, Lehmann F, Kern M. Influence of surface conditioning and cleaning methods on resin bonding to zirconia ceramic. Dent. Mater. 2011;27:207-213.

[10] Curtis AR, Wright AJ, Fleming GJ. The influence of surface modification techniques on the performance of a Y-TZP dental ceramic. J. Dent. 2006;34:195-206.

[11] Casucci A, Mazzitelli C, Monticelli F, et al. Morphological analysis of three zirconium oxide ceramics: effect of surface treatments. Dent. Mater. 2010;26:751-760.

[12] Casucci A, Monticelli F, Goracci C, et al. Effect of surface pre-treatments on the zirconia ceramic-resin cement microtensile bond strength. Dent. Mater. 2011;27:1024-1030. 
[13] Amaral R, Özcan M, Valandro LF, et al. Effect of conditioning methods on the microtensile bond strength of phosphate monomer-based cement on zirconia ceramic in dry and aged conditions. J. Biomed. Mater. Res. Part B: Appl. Biomater. 2008;85B:1-9.

[14] Shimada Y, Yamaguchi S, Tagami J. Micro-shear bond strength of dual-cured resin cement to glass ceramics. Dent. Mater. 2002;18:380-388.

[15] Andersson M, Odén A. A new all-ceramic crown. A dense-sintered, high-purity alumina coping with porcelain. Acta Odontol. Scand. 1993;51:59-64.

[16] Foxton RM, Cavalcanti AN, Nakajima M, et al. Durability of resin cement bond to aluminium oxide and zirconia ceramics after air abrasion and laser treatment. J. Prosthodont. 2011;20: 84-92.

[17] Özcan M, Raadschelders J, Vallittu P, et al. Effect of particle deposition parameters on silica coating of zirconia using a chairside air-abrasion device. J. Adhes. Dent. 2013;15:211-214.

[18] Soares LD, Basso GR, Spazzin AO, et al. Mechanical reliability of air-abraded and acid-etched bonded feldspar ceramic. Dent. Mater. 2016;32:433-441.

[19] Valandro LF, Özcan M, Bottino MC, et al. Bond strength of a resin cement to high-alumina and zirconia-reinforced ceramics: the effect of surface conditioning. J. Adhes. Dent. 2006;8:175-181.

[20] Yoshida K, Tsuo Y, Atsuta M. Bonding of dual-cured resin cement to zirconia ceramic using phosphate acid ester monomer and zirconate coupler. J. Biomed. Mater. Res. Part B: Appl. Biomater. 2006;77B:28-33.

[21] Özcan M, Cura C, Valandro LF. Early bond strength of two resin cements to Y-TZP ceramic using MPS or MPS/4-META silanes. Odontology. 2011;99:62-67.

[22] El-Korashy DI, El-Refai DA. Mechanical properties and bonding potential of partially stabilized zirconia treated with different chemomechanical treatments. J. Adhes. Dent. 2014;16:365-376.

[23] Şanlı S, Çömlekoğlu MD, Çömlekoğlu E, et al. Influence of surface treatment on the resinbonding of zirconia. Dent. Mater. 2015;31:657-668.

[24] Lawn BR, Deng Y, Lloyd IK, et al. Materials design of ceramic-based layer structures for crowns. J. Dent. Res. 2002;81:433-438.

[25] Soles CL, Yee AF. A discussion of the molecular mechanisms of moisture transport in epoxy resins. J. Polym. Sci., Part B: Polym. Phys. 2000;38:792-802.

[26] DeHoff PH, Anusavice kJ, Wang Z. Three-dimensional finite element analysis of the shear bond test. Dent. Mater. 1995;11:126-131.

[27] Braga RR, Meira JBC, Boaro LCC, et al. Adhesion to tooth structure: a critical review of "macro" test methods. Dent. Mater. 2010;26:e38-e49.

[28] Miragaya L, Maia LC, Sabrosa CE, et al. Evaluation of self-adhesive resin cement bond strength to yttria-stabilized zirconia ceramic (Y-TZP) using four surface treatments. J. Adhes. Dent. 2011;13:473-480.

[29] Craciunescu E, Sinescu C, Negrutiu ML, et al. Shear bond strength tests of zirconia veneering ceramics after chipping repair. J. Adhes. Sci. Technol. 2016;30:666-676. 